\title{
Correction to: Spontaneous and repeat spontaneous abortion risk in relation to occupational characteristics among working Korean women: a cross-sectional analysis of nationally representative data from Korea
}

\author{
Wanhyung Lee', Sung Won Jung ${ }^{2}$, Young-Mee Lim³ ${ }^{3}$ Kyung-Jae Lee ${ }^{2}$ and June-Hee Lee ${ }^{2^{*}}$
}

Correction to: BMC Public Health (2019) 19:1339

https://doi.org/10.1186/s12889-019-7728-7

It was highlighted that the original article [1] contained a mismatch between the result section of the abstract and Table 2. This Correction article shows the incorrect and correct result section of this article's Abstract.

\section{Incorrect statement:}

SA occurrence was reported in $5.7 \%$ of the study participants. The ORs (95\% CIs) for SA were significantly higher in pink-, green-, and blue-collared workers than in white-collared workers. Regarding weekly working hours, compared with $\leq 50 \mathrm{~h}$ spent working, the ORs (95\% CIs) for $51-60,61-70$, and $>70 \mathrm{~h}$ per week were 1.26 (0.87-1.84), 1.63 (1.04-2.56), and 1.73 (1.10-2.70), respectively. A significantly higher weighted prevalence of repeat SAs was observed in pink- and green-collared workers and in those who worked long hours.

\section{Correct statement:}

SA occurrence was reported in $5.7 \%$ of the study participants. The ORs $(95 \% \mathrm{CIs})$ for SA were significantly higher in pink-, green-, and blue-collared workers than in white-collared workers. Regarding weekly working hours, compared with $\leq 50 \mathrm{~h}$ spent working, the ORs (95\% CIs) for $51-60,61-70$, and $>70 \mathrm{~h}$ per week were
1.08 (0.72-1.62), 1.56 (1.02-2.45), and 1.66 (1.07-2.59), respectively. A significantly higher weighted prevalence of repeat SAs was observed in pink- and green-collared workers and in those who worked long hours.

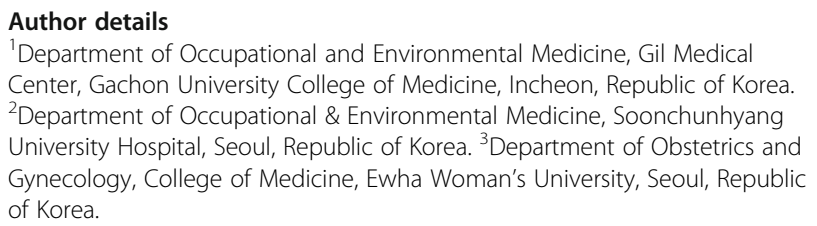

Published online: 16 December 2019

\section{Reference}

1. Lee W, et al. Spontaneous and repeat spontaneous abortion risk in relation to occupational characteristics among working Korean women: a crosssectional analysis of nationally representative data from Korea. BMC Public Health. 2019;19:1339. https://doi.org/10.1186/s12889-019-7728-7.

The original article can be found online at https://doi.org/10.1186/s12889019-7728-7

* Correspondence: junelee@schmc.ac.kr

${ }^{2}$ Department of Occupational \& Environmental Medicine, Soonchunhyang

University Hospital, Seoul, Republic of Korea

Full list of author information is available at the end of the article 